\title{
Regeneración ósea como un ejemplo de ingeniería tisular en odontología, con énfasis en el desarrollo de los andamios
}

\author{
Bone regeneration as an example of tissue engineering in \\ dentistry, with emphasis on the development of scaffolds \\ Regeneração óssea como exemplo de engenharia de tecidos em \\ odontologia, com ênfase no desenvolvimento de andaimes.
}

\author{
Sofia Curbelo ${ }^{1}$ ORCID: 0000-0001-6530-7116 \\ Romina Meneses ${ }^{1}$ ORCID: 0000-0001-7199-248 \\ Vanesa Pereira-Prado² ORCID: 0000-0001-7747-671 \\ Gabriel Tapia ${ }^{3}$ ORCID:0000-0001-7747-671
}

\section{Resumen}

La ingeniería tisular es un área científica multidisciplinaria la cual tiene como finalidad terapéutica restaurar, sustituir o incrementar las actividades funcionales de los tejidos orgánicos. Objetivos: Realizar una revisión de la literatura sobre la ingeniería tisular a nivel del área bucomaxilofacial. Métodos: Se realizó una búsqueda bibliográfica mediante los portales PubMed MEDLINE, Google Scholar, y LILACS, usando los términos "células madre, regeneración ósea y factores de crecimiento tisular”. Resultados: Se obtuvieron 193 resultados positivos, de los cuales 24 se utilizaron para el desarrollo del presente trabajo. Discusión: Han sido expuestos varios biomateriales capaces de propiciar la neoformación ósea, siendo esencial su correcta manipulación, la conformación de una arquitectura adecuada y la sinergia de las diversas propiedades. Conclusiones: Los andamios son los que brindan mayor oferta para su uso y la elección de cada uno de ellos no depende del material en sí mismo.

Palabras clave: ingeniería tisular, células madre, regeneración ósea y factores de crecimiento.

Facultad de Odontología, Universidad de la República, Montevideo, Uruguay.

Área de Patología Molecular Estomatológica, Facultad de Odontología, Universidad de la República, Montevideo, Uruguay.

Cátedra de Histología, Facultad de Odontología, Universidad de la República. Montevideo, Uruguay. 


\section{Abstract}

Tissue engineering is a multidisciplinary scientific area which has the therapeutic purpose of restoring, replacing or increasing the functional activities of organic tissues. Objectives: The objective of this work is to review the literature on tissue engineering at the level of the bucomaxilofacial area. Methods: A bibliographic search was carried out through the portals PubMed MEDLINE, Google Scholar and LILACS, using the terms "stem cells, bone regeneration and tissue growth factors". Results: 193 positive results were obtained, of which 24 were used for the development of this work. Discussion: Several biomaterials capable of promoting bone neoformation have been exposed, its correct manipulation, the conformation of an adequate architecture and the synergy of the various properties being essential. Conclusions: Scaffolds are the ones that offer the greatest offer for their use and the choice of each one does not depend on the material itself.

Keywords: tissue engineering, stem cells, bone regeneration and growth factors.

\section{Introducción}

La ingeniería tisular es un área científica multidisciplinaria en continua expansión cuyo objetivo es la construcción de un tejido igual o lo más parecido posible al tejido original dañado. En los últimos años ha experimentado un creciente interés en las ciencias de la salud lo que ha llevado a un gran número de investigaciones. Su utilización terapéutica, tiene como finalidad restaurar, sustituir o incrementar las actividades funcionales de los tejidos orgánicos ${ }^{(1,2)}$. Se asienta sobre los conocimientos de la histología,

\section{Resumo}

A engenharia de tecidos é uma área científica multidisciplinar cujo objetivo é restaurar, substituir e aumentar as atividades funcionais dos tecidos orgânicos. Objetivos: $\mathrm{O}$ objetivo deste trabalho é revisar a literatura sobre engenharia de tecidos no nível da área bucomaxilofacial. Métodos: Foi realizada uma pesquisa bibliográfica no portals PubMed MEDLINE, Google Scholar, e LILACS, utilizando os termos "células-tronco, regeneração óssea e fatores de crescimento tecidual". Resultados: foram obtidos 193 resultados positivos, dos quais 24 foram utilizados para o desenvolvimento deste trabalho. Discussáo: Vários biomateriais capazes de promover a neoformação óssea foram expostos, sendo sua manipulação correta, a conformação de uma arquitetura adequada e a sinergia das várias propriedades. Conclusóes: são os andaimes que oferecem a melhor oferta para seu uso e a escolha de cada um não depende do material propriamente dito.

Palavras-chave: engenharia de tecidos, células-tronco, regeneração óssea e fatores de crescimento.

disciplina que desde el ámbito de la docencia está condicionada por la investigación y esta área, tiene como fin último la construcción de un nuevo tejido ${ }^{(3,4)}$.

Esto requiere aislar y cultivar células en el laboratorio y disponer de biomateriales capaces de sustituir las matrices extracelulares, los cuales deberían presentar un comportamiento similar a los tejidos que sustituirán ${ }^{(3)}$.

El objetivo del presente artículo es realizar una revisión bibliográfica sobre el recorrido de la ingeniería tisular aplicada al tejido óseo en la esfera bucomaxilofacial. 


\section{Metodología}

Se realizó una búsqueda bibliográfica en mayo de 2019, utilizando la base de datos PubMed MEDLINE, Google Scholar y LILACS, incluyendo artículos de los últimos 6 años. Para esto fueron utilizados los siguientes descriptores: células madre, regeneración ósea y factores de crecimiento. La estrategia de búsqueda ha sido: ("Stem Cells" [Mesh]) AND "Bone Regeneration"[Mesh] AND "growth factors" AND ("last 6 years"[PDat]). Se incluyeron artículos tanto en idioma inglés como en español basados en reporte de casos, revisiones de la literatura y revisiones sistemáticas. Se obtuvieron 193 resultados positivos, de los cuales 24 se utilizaron para el desarrollo del presente trabajo.

\section{Desarrollo}

\section{Nacimiento y evolución de la teoría celular}

A principios del siglo XVII, las células fueron vistas y descritas por primera vez por A. van Leeuwenhoek (1632-1723), naturalista holandés, que se dedicó a investigarlas mediante cristales de aumento ${ }^{(5)}$.

El naturalista Buffon (1707-1788), expone que los seres microscópicos representan moléculas vivientes de las cuales, por aglomeración, resulta el animal visible. Todas estas ideas filosóficas fueron la fuente, junto con la experiencia y la observación a través del microscopio, de dónde provino la teoría de que en el cuerpo animal y en el vegetal aparecen pequeños "poros", ahora conocidos como células ${ }^{(5)}$.

Wolff era profesor de filosofía y fue el fundador de la teoría epigenética de la evolución, la cual proponía que "durante el desarrollo del individuo se forman nuevas estructuras a partir de un material no diferenciado, con ayuda de una fuerza vital" (5).

Pero fue el botánico inglés Robert Hooke quien, en 1665, introduce la palabra "célula" para designar las primeras cámaras que había observado al estudiar al microscopio delgadas láminas de tejidos vegetales. Si bien es pionero en su nomenclatura y en describir su estructura y esqueleto, nunca dimensionó su significado real. No fue hasta mediados del siglo XIX que los científicos alemanes Schleiden y Schwann, descubrirán la naturaleza celular de la materia viva afirmando que el organismo era un conglomerado de otros seres de orden inferior que, según ciertas leyes, se aglomeraban para confirmarlo. Ambos concluyeron que "la célula es la unidad estructural básica de todos los organismos". Plantean en su teoría celular que "Todo organismo vivo está constituido por una o por multitud de células"(5).

Rudolf Virchow (1821 - 1902). En su trabajo "Patología celular" (1858), consideró la célula como la unidad básica metabólica y estructural del ser vivo, así como propone que "todas las células provienen de otras células (preexistentes)"(5).

Lo propuesto en 1839, por Schleiden y Schwann, sumado a lo expuesto en 1858 por Virchow, contribuyó ampliamente a la Teoría Celular tal como se la considera hoy, que puede resumirse en los siguientes principios:

1. Las funciones vitales de los organismos ocurren en las células o en su entorno inmediato, controladas por sustancias que ellas secretan. En ella caben todas las funciones vitales, basta una célula para tener un ser vivo. La célula es la unidad fisiológica de la vida.

2. Todas las células proceden de células preexistentes, por división de éstas. Es la unidad de origen de todos los seres vivos.

3. Cada célula contiene toda la información hereditaria necesaria para el control de su propio ciclo y del desarrollo y el funcionamiento de un organismo de su especie, así como para la transmisión de esa información. La célula es la unidad genética ${ }^{(5)}$.

\section{Evolución en el estudio de células madre}

Ernst Haeckel (biólogo, médico y filósofo alemán) expone por primera vez el término 
"Stammzelle" (“células troncales") para denominar al organismo unicelular que habría sido el antepasado común de todos los organismos multicelulares. Este ancestro se originaría a partir de las formas de vida más primitivas a las que llamó "Moneren” (del griego moneres, simple). El médico alemán estudió y comparó el desarrollo de embriones de diversas especies, lo cual lo llevó a concluir que, mientras más temprana es la etapa observada, más se asemejan entre sí los individuos de diferentes especies, llegando al punto de ser indistinguibles. Fue entonces que formuló la "ley biogenética", en la que expresa que el desarrollo embrionario es una versión acelerada y resumida del proceso de evolución de cada especie ${ }^{(6)}$.

Bajo este contexto, Haeckel utilizó nuevamente el término célula troncal para denominar al huevo fecundado o "cigoto". Al tratarse de la fase más precoz del desarrollo representaría el origen común de todos los organismos multicelulares, dejando en claro la especial condición de éste como la célula precursora de todas las células del organismo adulto ${ }^{(6)}$.

En el transcurso de la década de 1890, August Weismann plantea en su teoría de la continuidad del "plasma germinal" que los organismos multicelulares se constituyen de "células germinales" que contienen y transmiten la herencia y, de "células somáticas" que forman el resto del organismo y llevan a cabo las funciones corporales. Dentro de este contexto Theodor Bovery (1862-1927) observó mediante la representación de las etapas embrionarias tempranas del gusano Ascaris megalocephala, que las células troncales, "células germinales primordiales", eran un subgrupo de células derivadas del cigoto que durante el desarrollo tenían la particularidad de dividirse dando origen tanto a una célula precursora de las células somáticas, como a otra célula semejante a sí misma ${ }^{(6)}$.

Es destacable que en este momento de la historia ya habían sido descritas las características esenciales que definen hoy en día el concepto de células madre o troncales: "son células indiferen- ciadas (indiferenciación), que tienen la capacidad de dar origen a células idénticas a si mismas (auto renovación) y a la vez, de diferenciarse a otros tipos de células especializadas (plasticidad)" (6).

En la misma época, se llevaba a cabo el estudio de la formación, desarrollo y regeneración del sistema hematopoyético. En base a lo estudiado sobre las células troncales en el área de la embriología, aparece la incógnita de si habría un precursor común para los distintos tipos celulares de la sangre. Artur Pappenheim (18701916) se dedicó al estudio de la hematopoyesis ocurrida durante el desarrollo embrionario de anfibios. Elaboro diagramas que representan la célula precursora de la sangre dando origen a los diversos linajes de células hematopoyéticas $y$, fue en uno de estos trabajos donde propuso el nombre "Mutterzellen" (célula madre) para denominar al precursor común, en 1896 en Berlín. Sin embargo, fue el investigador ruso Alexander Maximov (1874- 1928) quien, en 1909 oficialmente utilizó el término "Stamzelle" para nombrar a la célula precursora, reconociendo que tendría las propiedades de indiferenciación, autorenovación y plasticidad que ya habían sido descritas en la embriología. En 1963, los investigadores canadienses Ernest McCullock y James Till, realizaron una serie de experimentos que involucran la inyección de células de la médula ósea (MO) en ratones irradiados, observando que pequeños nódulos habían crecido en los bazos de los ratones, en proporción al número de células de $\mathrm{MO}$ inyectadas ${ }^{(6)}$. Cada nódulo era originado por una única célula a la que llamaron unidad formadora de colonias (UFC). Estos investigadores, en colaboración con Lou Siminovitch, obtuvieron pruebas de que estas células indiferenciadas eran capaces de autorrenovarse, así como, dar origen a todos los componentes de la sangre, cumpliendo con las características de una célula madre y demostrando definitivamente la existencia de la célula precursora común de la sangre. Dicha UFC sería llamada posteriormente célula madre hematopoyética ${ }^{(6)}$. 
En 1975 el equipo del Dr. Rheinwald, estableció el método estándar, mediante el cual se lograron las condiciones necesarias y fundamentales para cultivar de forma indefinida, este tipo de células ${ }^{(7)}$.

Es en 1980 cuando se consigue la primera aplicación clínica de células madre, mediante el equipo del Dr. Banks-Schelegel quienes obtienen epitelio cutáneo in vitro y demuestran su viabilidad empleando como injerto en animales de experimentación.

En 1981, los científicos británicos Martin Evans y Matthew Kaufman aíslan y cultivan exitosamente células madre embrionarias de ratón, de la masa celular interna del blastocito ${ }^{(8)}$.

El término "célula madre" oficialmente entró en el contexto científico cuando éstas fueron utilizadas por los histo-embriólogos Theodor Boveri y Valentin Haeckel, quienes describieron las características hereditarias de las células germinales y su pluripotencialidad, así como su autorrenovación ${ }^{(8)}$.

En 1998, la revista Science publicó que el profesor Thomson de la Universidad de Wisconsin había desarrollado la primera línea de células madre embrionarias humanas, derivadas exitosamente de la masa celular interna de un blastocito producido por fertilización in vitro ${ }^{(8)}$.

\section{Ingeniería tisular en la actualidad}

El término ingeniería tisular fue introducido en 1987 por Fung, siendo un área científica interdisciplinaria que se dedica a la construcción de tejidos biológicos artificiales y su utilización terapéutica con la finalidad de restaurar, sustituir o incrementar las actividades funcionales de los tejidos orgánicos. Se basa en el empleo de células vivas, la manipulación del entorno extracelular, creando sustitutos biológicos que, finalmente se implantará en el organismo. Es un área en continua expansión, que se asienta sobre los conocimientos de la histología y tiene por fin último la construcción de un nuevo tejido a partir de células procedentes de cultivos y biomateriales que servirán como soporte ${ }^{(9)}$.
El proceso de investigación y el desarrollo en el área, ha contribuido significativamente al establecimiento de la ingeniería tisular como una opción de tratamiento viable en medicina y odontología.

Dentro de esta área, es imprescindible la participación de tres componentes fundamentales: células madre, andamios, que son sustratos insolubles, y factores de crecimiento, que producen la señal osteoinductora para la neoformación ósea ${ }^{(7)}$. Por ser los tres igual de necesarios para el desempeño de una terapia celular, describiremos cada uno de ellos.

Las células madre son células con capacidad de dividirse de manera continua, así como de producir células progenitoras capaces de dar lugar a células especializadas. La alta capacidad de diferenciarse que éstas presentan se denomina plasticidad $^{(10)}$.

Podemos clasificar a las células madre según su momento de origen y su potencial para formar células especializadas. Así como también, pueden dividirse según su potencialidad, siendo la potencia celular la capacidad que tiene la célula de diferenciarse.

Tomando el primer criterio, diremos que existen células madre de tipo embrionarias y postnatales. Las células embrionarias se producen a partir de la fecundación del óvulo. Una vez que esto ocurre, se forma el blastocito, siendo este una esfera de aproximadamente 100 células, con una capa externa denominada trofoblasto, una cavidad llena de líquido, el blastocele y una masa celular en su interior. Es en la etapa de blastocito donde se podrían aislar células madre ${ }^{(11)}$.

Por otro lado, tenemos las células madre postnatales, siendo éstas, células indiferenciadas ubicadas en tejidos u órganos, entre otras células ya especializadas. Tienen la cualidad de diferenciarse según la necesidad del tejido u órgano en el cual se alojan, contribuyendo a la homeostasis del organismo y reparación de tejidos ${ }^{(11)}$. El segundo criterio de clasificación, puede dividir a las células madre según su potencialidad, 
siendo la potencia celular la capacidad que tiene la célula de diferenciarse. En este contexto podemos reconocer células madre totipotenciales, pluripotenciales, multipotenciales y unipotentes. Las totipotenciales, tienen la capacidad de dividirse y producir cualquier célula del organismo, incluso dar lugar a todo un individuo, esta cualidad la expresan las células madre embrionarias. Las pluripotenciales, son células madre que tienen la capacidad de diferenciarse en cualquier linaje celular de tejido endodérmico, mesodérmico o ectodérmico. Las multipotenciales, son aquellas células diferenciadas que pueden formar varios tipos de tejido, a partir de tejido fetal, de sangre de cordón umbilical o de células madre postnatales. Por último, las unipotentes pueden formar únicamente un tipo de célula particular ${ }^{(11)}$ (véase Fig. 1) ${ }^{(10)}$.

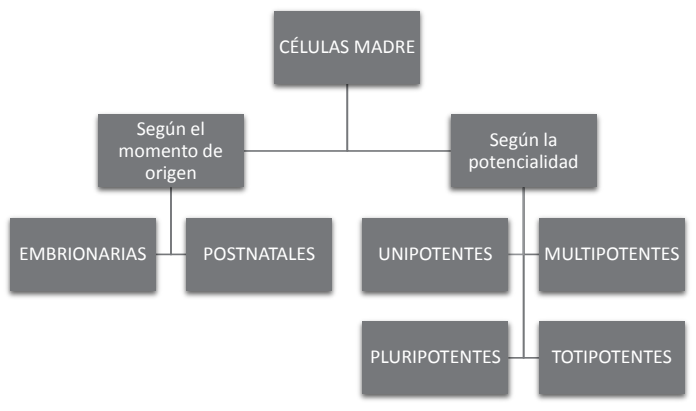

Fig. 1. Clasificación de células madre. Modificado de Redón, J. ${ }^{(10)}$

En el área odontológica las células madres postnatales son las que se pueden apreciar en la Tabla 1.

\section{CÉLULAS MADRE MESENQUIMÁTICAS}

DPSCs (Dental Pulp Stem Cells)

SHEDs (Stem cells from Human Exfoliated Deciduos teeth)

PDLSCs (Periodontal Ligament Stem Cells)

DFSCs (Dental Follicle Stem Cells)

SCAPs (Stem Cells from the Apical Papila)

BMSSCs (Bone Marrow Stromal Stem Cells)

SHEDs (Stem cells from Human Exfoliated Deciduos teeth)

PDLSCs (Periodontal Ligament Stem Cells)

DFSCs (Dental Follicle Stem Cells)

SCAPs (Stem Cells from the Apical Papila)

BMSSCs (Bone Marrow Stromal Stem Cells)

\section{CÉLULAS MADRE EPITELIALES}

ABCs (Apical Bud Cells) roedores

Epitelio de Lámina Dentaria (3er molar - órgano del esmalte mes 72)

Epitelio de Mucosa Oral

Epitelio de Glándulas Salivales

Tabla 1. Células madre posnatales diferenciadas en mesenquimaticas y epiteliales. (Elaboración propia)

Otro elemento básico para el desarrollo de la Ingeniería Tisular son los andamios o "scaffolds", que actúan como una matriz extracelular temporal $^{(12)}$ creando el microambiente tridimensional necesario para conseguir el crecimiento y la diferenciación celular, además promueve la adhesión y la migración celular, facilitando la formación de tejidos funcionales y órganos ${ }^{(10)}$.
Para conseguir las condiciones necesarias antedichas, los andamios deben cumplir con una serie de requisitos tales como: alta porosidad y un adecuado tamańo del poro, necesario para facilitar el cultivo y la difusión de nutrientes a través de la estructura de las células; gran área de superficie y buena degradación. Deben ser biocompatibles e interactuar positivamente con 
otras células de adhesión, crecimiento y migración. Además, deben presentar buena resistencia física y mecánica ${ }^{(10)}$.

En el área odontológica el diseño de los andamios es complejo, ya que deben encajar en un defecto anatómico tridimensional y debe ser temporalmente liberado de cargas, hasta la formación de nuevo tejido óseo ${ }^{(12,13)}$.

Dependiendo de cómo estén compuestos, los andamios pueden ser clasificados como:

- Naturales, Orgánicos o Biodegradables

- Sintéticos, Inorgánicos o Permanentes ${ }^{(12)}$.

Los primeros se construyen utilizando componentes de la matriz extracelular, siendo pertinente para ello derivados proteicos como colágeno, fibrinógeno, ácido hialurónico, glucosaminoglucanos, hidroxiapatita, etc ${ }^{(12)}$.
Tienen como ventaja ser bioactivos, biocompatibles y presentar propiedades mecánicas similares a las de un tejido natural. Mientras que las desventajas que éstos presentan es que permiten un control limitado sobre las propiedades fisicoquímicas, tienen dificultad en la tasa de degradación y en la esterilización y purificación de patógenos cuando es aislado de diferentes fuentes ${ }^{(12)}$.

Dentro de este grupo contamos con andamios porosos tridimensionales. (Véase Fig. 2). Consisten en una red de interconexión macroporosa con diámetros de al menos $100 \mu \mathrm{m}$ que son requeridos para facilitar el crecimiento de las células, la vascularización, la producción de matriz extracelular temporal y la eliminación de material de desecho ${ }^{(12)}$.

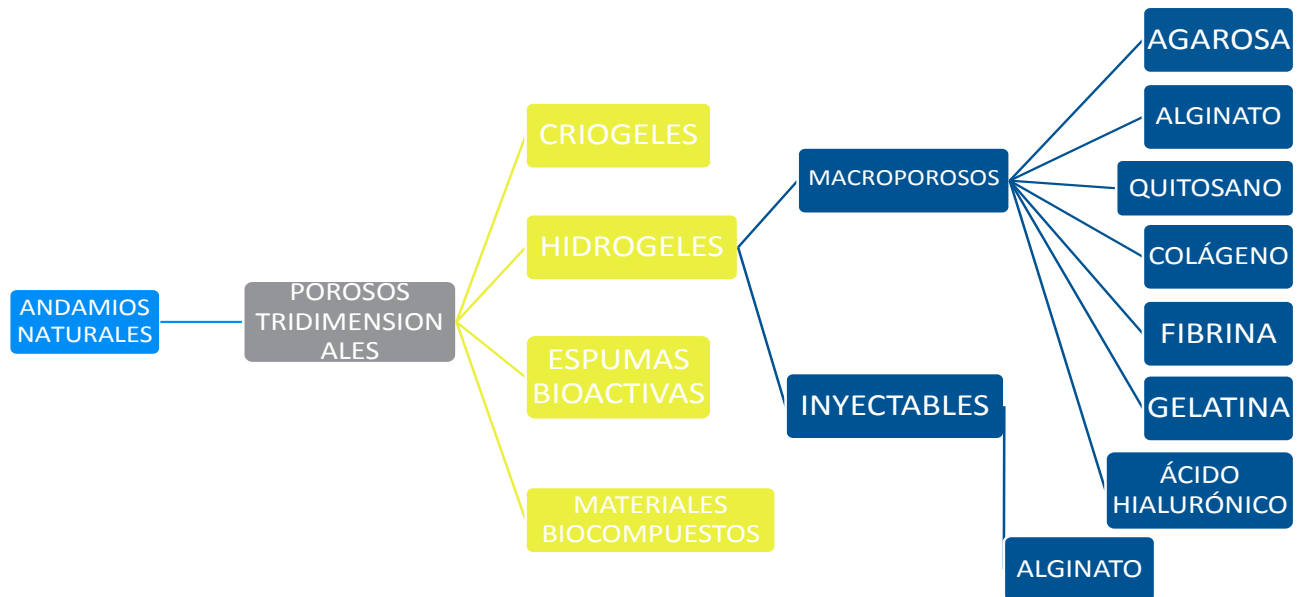

Fig. 2. Materiales que comprenden los andamios porosos tridimensionales.

Dentro de los andamios más utilizados encontramos los basados en hidrogeles; estos pueden ser macroporosos o inyectables. Se componen de un polímero hidrofílico que forma redes tridimensionales. Suelen hincharse rápidamente en contacto con el agua, forman macromoléculas que son estructuralmente similares a componentes del cuerpo $y$, tienen una excelente biocompatibilidad con mínima respuesta in- flamatoria. Su arquitectura hidratada inherente permite transporte de factores solubles, nutrientes y desechos. El tamaño y la distribución de poros, así como la interconectividad entre ellos, son factores importantes que rigen el uso de hidrogeles en la ingeniería de tejidos, siendo esto crítico para que las células se distribuyen dentro del gel ${ }^{(12,13)}$. 
De los polímeros naturales, el alginato es un biomaterial bien establecido debido a su bajo costo, biocompatibilidad y simple solidificación. Son ampliamente utilizados en la reparación de cartílago y tejido óseo. Sin embargo, su biocompatibilidad depende de muchos factores como su composición, peso molecular, y los contaminantes presentes en el gel ${ }^{(12,13)}$.

Los hidrogeles inyectables ganaron una considerable atención debido a que forman un gel in vivo. Esta propiedad es una gran ventaja de uso en la ingeniería tisular, ya que se puede manejar la gelación in situ del líquido a los materiales de hidrogel, permitiendo que los hidrogeles llenen defectos de cualquier tamaño o forma ${ }^{(12,13)}$.

Estos materiales también funcionan como un soporte líquido dinámico para transportar las células vivas, las medicaciones y los factores de crecimiento que se requieren para que el tejido se regenere ${ }^{(12,13)}$.
Las microesferas de alginato cargadas en una pasta de fosfato de calcio fueron probadas para su inyectabilidad, con la finalidad de reconstruir tejido óseo craneofacial, y los resultados mostraron diferenciación osteogénica mejorada en presencia de calcio, fosfato y quitosano ${ }^{(12,13)}$. Por su parte el colágeno ha recibido una atención creciente debido a su excelente biocompatibilidad, a su capacidad de degradarse en productos fisiológicos y al hecho de que produce una interacción adecuada con células y otras macromoléculas. El principal inconveniente de los andamios de colágeno puro radica en sus bajas propiedades mecánicas, que no se acercan a las del tejido óseo natural ${ }^{(14,15,16)}$.

En cuanto a los andamios sintéticos, inorgánicos o permanentes podemos enunciar entre estas matrices a polímeros, cerámicas y metales. (Ver Fig. 3).

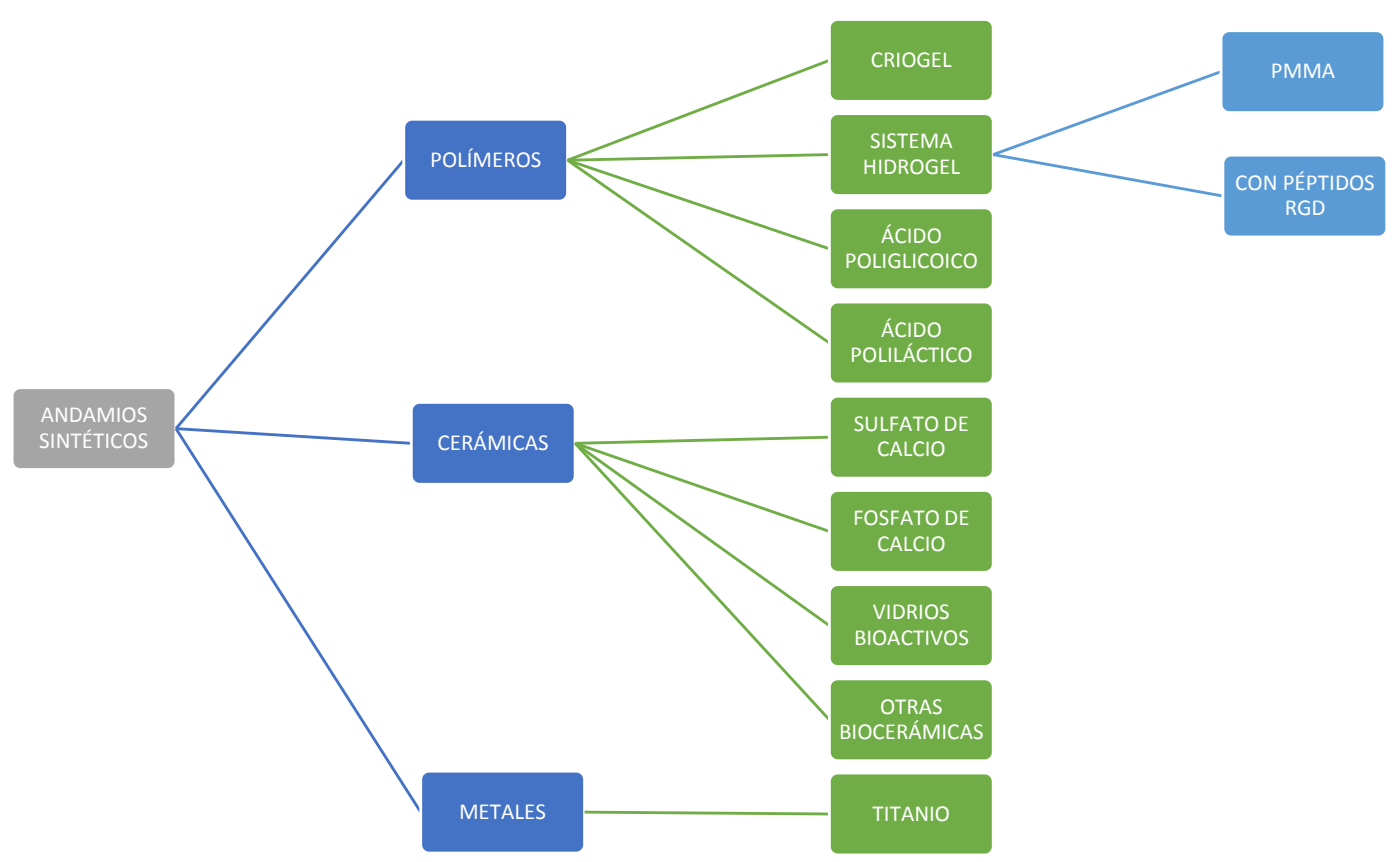

Fig. 3. Materiales que comprenden los andamios sintéticos 
Los criogeles, son hidrogeles que se sintetizan a temperaturas bajo cero para obtener buena porosidad y resistencia mecánica. Son sintetizados a bajas temperaturas por productos químicos o físicos, por medio de gelificación de cadenas poliméricas, o polimerización de radicales libres de precursores monoméricos.

La resistencia a la transferencia de masa es despreciable en estos criogeles debido a la microporosidad y conectividad entre los poros, lo que permite la circulación suave de nutrientes a las células en crecimiento ${ }^{(12,13)}$.

Los hidrogeles inyectables de polimetilmetacrilato (PMMA) se han utilizado durante mucho tiempo para asegurar implantes ortopédicos en el esqueleto humano. El PMMA generalmente se usa en forma de monómeros con una mezcla de iniciador, mezclado a temperatura ambiente, que polimeriza cuando se inyecta en el cuerpo. Estos polímeros tienen la capacidad de volverse gelatinosos fácilmente dentro del organismo en presencia de fotoiniciadores o termoiniciadores. Son biodegradables, mecánicamente fuertes, y capaces de soportar el crecimiento de osteoblastos. Sin embargo, sus usos se limitan a la entrega de células como las células osteoprogenitoras, porque su reticulación durante la fotopolimerización puede afectar la viabilidad de las células ${ }^{(10)}$.

El ácido poliglicólico (PGA) y el ácido poliláctico (PLA), son polímeros usados frecuentemente en el desarrollo de andamios sintéticos en 3-D. Estos materiales son hidrolíticamente degradables, se puede controlar con facilidad la tasa de degradación y, además, proporcionan versatilidad en la creación de microambientes tridimensionales. Como desventaja, se destaca su escasa bioactividad ${ }^{(10)}$.

Dentro de los materiales cerámicos el fosfato de calcio $(\mathrm{CaP})$ ha sido ampliamente investigado en la regeneración ósea en forma de cementos, recubrimientos y andamios celulares tridimensionales porque tiene excelentes propiedades osteoconductivas $^{(10,14)}$.
Es un material biocompatible, de bajo costo y fácil de sintetizar ${ }^{(12,13)}$. Sus principales ventajas incluyen la similitud en composición del CaP con Hidroxiapatita, la capacidad de las células osteoprogenitoras de procesar y reabsorber materiales a base de $\mathrm{CaP}$ y el complejo, pero altamente efectivo, sistema de señalización intracelular de la osteogénesis que se desencadena por la presencia de calcio soluble y fosfatos inorgánicos resultantes de subproductos de disolución del cristal de $\mathrm{CaP}$.

Actualmente, existe una gran cantidad de materiales a base de $\mathrm{CaP}$ que son comercializados para regeneración ósea ${ }^{(14,17,16,18)}$.

Están formados por una combinación de concentraciones de hidroxiapatita como fase estable, y fosfato de calcio como fase soluble. La bioactividad de estas cerámicas se puede controlar manipulando las proporciones de esos componentes ${ }^{(12,13)}$.

El sulfato de calcio ( $\mathrm{CaSO} 4)$ se ha utilizado en odontología clínica implantaria, cirugía craneofacial, corrección de la hendidura alveolar en niños, cirugía endodóntica perirradicular y cirugía ortopédica, consiguiendo resultados efectivos y consistentes.

Los compuestos de sulfato de calcio y fosfato de calcio imitan la fase mineral del tejido óseo. Estos materiales inducen una respuesta biológica similar a la generada durante el remodelado óseo, creando un entorno rico en calcio en el área de la implantación.

Walsh et al. ${ }^{(19)}$ sugirieron que la disminución del pH y la acidez local producida durante la resorción de sulfato de calcio, causaba una desmineralización del hueso adyacente $y$, re transfieren las BMP unidas a la matriz. Además, el aumento de la angiogénesis en los sitios tratados con sulfato de calcio podría explicar los buenos resultados informados ${ }^{(11)}$.

Algunos autores ${ }^{(20)}$ aseguran recientemente que andamios basados en Folato de estroncio aumentan la regeneración ósea in vivo y los proponen como una alternativa útil para la regeneración de tejido óseo en defectos complicados ${ }^{(20)}$. 
Por otra parte, los metales pueden ser utilizados para la realización de un andamio. El más aceptado es el titanio, debido a que posee gran biocompatibilidad y alta sinergia con el tejido óseo. Es usado ampliamente en ortopedia y cirugía oral ${ }^{(10)}$.

El potencial osteoinductivo y vasculogénico de los andamios es potenciado por la introducción de factores de crecimiento apropiados que induce la quimiotaxis, la proliferación y diferenciación de las células encapsuladas y circundantes ${ }^{(14)}$.

Los factores de crecimiento, son el tercer elemento necesario para desencadenar una terapia de ingeniería tisular. Son proteínas que se unen a receptores de la célula e inducen proliferación celular y/o cito diferenciación. Estos son utilizados para controlar la actividad de las células madre, aumentando la tasa de proliferación, induciendo la diferenciación de las células en otro tipo de tejido, estimulando las células madre para sintetizar y secretar matriz mineralizada y, para inducir la regeneración de tejidos lesionados ${ }^{(10)}$.

Actualmente, se conocen dos categorías de biofactores que estimulan las actividades osteogénicas de las células. La primera, induce la transformación de células no osteoblásticas en osteoblastos. La segunda, aumenta la proliferación y actividad de los osteoblastos, acelerando así la osificación y la formación de la matriz ósea, efecto conocido como modulación. Ambos, inducción y modulación, funcionan de manera sinérgica ${ }^{(14,18,21,22,23)}$ (Tabla 2).

\begin{tabular}{|c|c|c|}
\hline FACTOR DE CRECIMIENTO & LOCALIZACIÓN & FUNCIÓN \\
\hline $\begin{array}{l}\text { TGF- } \beta \text {. Factor de crecimien- } \\
\text { to y transformación beta }\end{array}$ & $\begin{array}{l}\text { Matriz dentinal. } \\
\text { Secretado por los odontoblas- } \\
\text { tos y durante la activación de } \\
\text { linfocitos T helper y Natural } \\
\text { Killer. }\end{array}$ & $\begin{array}{l}\text { - Señalización celular para la diferenciación de los odontoblastos y en } \\
\text { la estimulación de la secreción de matriz de dentina. } \\
\text { - Promotor de la mineralización del tejido dentinario. } \\
\text { - Promotor del mecanismo antiinflamatorio, promueve la reparación, } \\
\text { inhibe la proliferación de macrófagos y leucocitos }\end{array}$ \\
\hline $\begin{array}{l}\text { BMP. Proteína morfogené- } \\
\text { tica ósea. }\end{array}$ & Matriz ósea. & $\begin{array}{l}\text { - Estimulan la diferenciación de células madre postnatales pulpares, la } \\
\text { regeneración de tejidos periodontales e inducen la diferenciación de } \\
\text { osteoblastos y la mineralización ósea. } \\
\text { - Se utiliza in IT para sintetizar células madre y lograr la secreción de } \\
\text { matriz mineral. }\end{array}$ \\
\hline $\begin{array}{l}\text { FGF. Factor de crecimiento } \\
\text { fibroblástico. }\end{array}$ & Amplio rango de células & $\begin{array}{l}\text { - Promueve la proliferación celular. } \\
\text { - Influencia inhibitoria en la proliferación de células inmaduras, ya que, } \\
\text { su función principal es limitar la ontogénesis. } \\
\text { - En IT es útil para aumentar el número de células. }\end{array}$ \\
\hline $\begin{array}{l}\text { PDGF. Factor de crecimiento } \\
\text { derivado de plaquetas. }\end{array}$ & $\begin{array}{l}\text { Placenta } \\
\text { Células endoteliales } \\
\text { Plaquetas }\end{array}$ & $\begin{array}{l}\text { - Promover la proliferación de tejido conjuntivo y células del músculo } \\
\text { liso. } \\
\text { - Utilizado en IT para incrementar el número de células madre. } \\
\text { - Involucrado en la curación de heridas, reparación ósea y remodelado } \\
\text { durante trauma o infección, por inducir la proliferación de células } \\
\text { precursoras osteoblásticas. }\end{array}$ \\
\hline $\begin{array}{l}\text { CSF. Factor estimulante de } \\
\text { colonias. }\end{array}$ & Amplio rango de células & $\begin{array}{l}\text { - Estimular la proliferación de células madre pluripotenciales óseas. } \\
\text { - Su uso en IT es incrementar el número de células madre. }\end{array}$ \\
\hline $\begin{array}{l}\text { EGF. Factor de crecimiento } \\
\text { epidermal. }\end{array}$ & Glándulas submaxilares & $\begin{array}{l}\text { - Incrementar el número de células madre, dado que promueve la } \\
\text { proliferación de células mesenquimales y epiteliales. }\end{array}$ \\
\hline $\begin{array}{l}\text { IGF. Factor de crecimiento } \\
\text { insulínico o somatomedina. }\end{array}$ & $\begin{array}{l}\text { Se sintetiza en muchos tejidos, } \\
\text { principalmente el hígado. }\end{array}$ & - Crecimiento general y mantenimiento del esqueleto corporal. \\
\hline $\begin{array}{l}\text { VEGF. Factor de crecimiento } \\
\text { vascular endotelial }\end{array}$ & Amplio rango de células & $\begin{array}{l}\text { - Proliferación, vascularización y osificación durante la formación de } \\
\text { tejido óse0. }\end{array}$ \\
\hline
\end{tabular}

Tabla 2. Factores de crecimiento implicados en odontología. (Elaboración propia) 


\section{Discusión}

La Ingeniería Tisular propone nuevas terapias innovadoras y revolucionarias que implican la regeneración o reemplazo de tejidos u órganos a través de constructos tridimensionales que devuelvan la forma y función. Estas pueden ser a partir de las propias células del paciente en conjunto con biomateriales y biomoléculas o a punto de partida de estructuras exógenas.

Cada una de las técnicas regenerativas en odontología presenta ventajas y desventajas, $y$ es de importancia saber que algunas se encuentran en proceso de desarrollo ${ }^{(14,15)}$.

Thrivikraman et al., plantean que los biomateriales son utilizados en forma de andamios biocompatibles que permiten la migración, proliferación y diferenciación tanto de células residentes como externas, utilizándose para promover la formación de nuevo tejido óseo $(14,15)$. Mijiritsky y colaboradores proponen además que los biomateriales son los encargados de brindar un sustrato tridimensional sobre el cual las células sean capaces de proliferar, necesitando para ello factores de crecimiento esenciales para cada tipo celular ${ }^{(24)}$. Los biomateriales son entonces, un punto fundamental dentro de la regeneración ósea ya que serán los encargados de propiciar y regular un microambiente favorable para desencadenar el proceso de neoformación ósea. En el desarrollo de este trabajo han sido expuestos varios biomateriales capaces de adaptarse a este rol, siendo esencial su correcta manipulación, la conformación de una arquitectura adecuada y la sinergia de las diversas propiedades que estos presentan para así propiciar el proceso de formación de nuevo tejido ${ }^{(12,13)}$.

Según plantean Shakya y colaboradores, diseñar un andamio para el área odontológica no es una tarea sencilla, estos deben encajar en un defecto anatómico tridimensional y ser temporalmente liberado de cargas, hasta que se produzca la neoformación ósea esperada ${ }^{(12)}$. Se deben tener muy presentes las características necesarias para conformar un andamio en esta área: porosidad adecuada, biocompatibilidad, degradabilidad, morfología superficial y resistencia mecánica. Otras características tales como bioactividad, favorecer la osteogénesis, bajo costo, son factores que también ayudan en la selección del material adecuado. Dentro de la gama de biomateriales expuestos, no existe uno que cumpla con todas las características ideales, por lo que no existe el material ideal para crear un andamio. Pero si, es necesario que cada caso sea estudiado en su particularidad y optar por el que satisfaga la mayor cantidad de necesidades para él. $\mathrm{Mu}$ chas veces es la combinación de biomateriales la que propicia el mejor andamio, buscando el sinergismo de sus características, mientras que en otras oportunidades, basta con optar

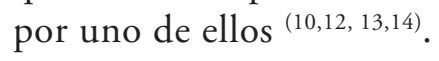

\section{Conclusiones}

Hemos realizado un recorrido histórico sobre la ingeniería tisular aplicada a la esfera bucomaxilofacial, en especial al tejido óseo, analizando los pilares de la misma como son las células madre, los factores de crecimiento y los andamios; éstos últimos son los que brindan mayor oferta para su uso y la elección de cada uno de ellos no depende del material en sí mismo, dado que no existe el material ideal, sino que dependerá de cada caso particular, tal como lo muestran los hallazgos del presente trabajo.

La aplicación de tratamientos de regeneración ósea basados en ingeniería tisular a nivel de los maxilares nos permite mejorar la calidad de vida de nuestros pacientes a través de terapias de vanguardia. 


\section{Contribución de autoría}

1. Concepción y diseño del estudio

2. Adquisición de datos

3. Análisis de datos

4. Discusión de los resultados

5. Redacción del manuscrito

6. Aprobación de la versión final del manuscrito

SC ha contribuido en 1, 2, 3, 4, 5, 6 . RM ha contribuido en 1, 2, 3, 4, 5, 6 . VP ha contribuido en $4,5,6$. GP ha contribuido en 4, 5, 6 .

\section{Referencias}

1. Piedra MAM, Espejo SA, Moral-Munoz JA,Campos F, Chato-Astrain J, Garcia-Garcia OD, Sanchez Porras D, Antonio Campos. An Evolutive and Scientometric Research on Tissue Engineering Reviews. Tissue Eng Part A. 2019; 26 (9-10): 569-577. doi: 10.1089/ten. TEA.2019.0247. [Epub ahead of print]

2. Espejo SA, Campos F, Piedra LM, Durand Herrera D, Moral-Munoz JA,Campos A, Piedra MAM. Global Tissue Engineering Trends: A Scientometric and Evolutive Study. Tissue Eng Part A. 2018; 24 (19-20): 1504-1517.

3. Piedra MAM, Alaminos M, Fernández Valadés Gámez R, España López A, Liceras-Liceras E, Sánchez Montesinos I, Martínez-Plaza A, Sánchez-Quevedo MC, R Fernández-Valadés, Garzón I. Development of a multilayered palate substitute in rabbits: a histochemical ex vivo and in vivo analysis. Histochem Cell Biol. 2017; 147(3): 377-388.

4. Gómez de Ferraris, Campos Muñoz. Histología, embriología e ingeniería tisular bucodental, 2019, 4ta edición, editorial Médica Panamericana. P3-36.

5. Berón MP. Historia de la teoría celular. Universidad Nacional de Mar del Plata. 2006.

6. Apablaza F. Antecedentes históricos y conceptos básicos en el estudio de las células madre: células troncales, o la madre de todas las células. Rev. Actuali. Clinic. Meds. 2017; 1(1): p6-16
7. Fernández González A, Lizana Moreno A, de Pablos Ramos M, Ruiz García A, Espinosa Ibáñez O, Fernández Porcel N, Guerrero Calvo J, Arrabal M, López-Carmona F, Arias-Santiago S. Optimización del cultivo de queratinocitos humanos para el desarrollo de un modelo de piel artificial humana: alternativas celulares como capa alimentadora. Real Academia de Medicina y Cirugía de Andalucía Oriental; Universidad de Granada. Agosto, 2016.

8. Smalley M, Ashworth A. Stem cells and breast cancer: a field in transit. Nature Reviews Cancer. 2003. 3: p832-844.

9. Gómez de Ferraris Ma.E, Campos Munóz A. Histología, embriología e ingeniería tisular bucodental. Tercera edición. 2009. Editorial médica Panamericana. p2-26 p381-392.

10. Redón J, Jiménes L P, Urrego P A. Células madre en odontología. Revista CES Odontología. 2011; 24 (1)

11. Aquino-Martínez R, Angelo A.P, Ventura Pujol F. Calcium-containing scaffolds induce bone regeneration by regulating mesenchymal stem cell differentiation and migration. Stem cell research \& therapy. 2017; 8: 265 p. doi: $10.1186 /$ s13287-017-0713-08.

12. Shakya A K, Kandalam U. Three-dimensional macroporous materials for tissue engineering of craniofacial bone. $\mathrm{Br} \mathrm{J}$ OralMaxillofacSurg. 2017; 55 (9): 875-891.

13. Lee CL, Hajibandeh J, Suzuki T, Fan A, Shang P, Mao JJ. Three-dimensional printed multiphase scaffolds for regeneration of periodontium complex. Tissue engineering Part A. 2014; 20 (7-8): 1342-51.

14. Thrivikraman G, Athirasala A, Twohig Ch, Kumar Boda S. Biomaterials for Craniofacial Bone Regeneration. Dent Clin North Am D. 2017; 61 (4): 835-856.

15. Habraken W, Habibovic P, Epple M, Bohner M. Calcium phosphates in biomedical applications: materials for the future. Materials Today. 2016; 19 (2): 69-87.

16. Stoppel WL, et al. Clinical applications of naturally derived biopolymer-based scaffolds for regenerative medicine. Ann Biomed Eng. 2015; 43 (3): 657-80.

17. Kang Y, Kim S, Fahrenholtz M, et al. Osteogenic and angiogenic potentials of monocultured and co-cultured human-bone-marrow-derived 
mesenchymal stem cells and human-umbilicalvein endothelial cells on three-dimensional porous beta-tricalcium phosphate scaffold. Acta biomaterialia. 2012; 9 (1): 4906-15.

18. Tollemar V, Collier ZJ, Mohammed MK, Lee MJ, Ameer GA 4, Russell R. Stem cells, growth factors and scaffolds in craniofacial regenerative medicine. Genes Dis. 2016; 3 (1): 56-71.

19. Walsh WR, Morberg P, Yu Y, Yang JL, Haggard W, Sheath PC, Svehla M, Bruce WJM. Response of a calcium sulfate bone graft substitute in a confined cancellous defect. Clin Orthop Relat Res. 2003; 406: 228-36.

20. Martín-Del-Campo M, Sampedro JG, FloresCedillo ML, Rosales-Ibañez R, Rojo L. Bone Regeneration Induced by Strontium Folate Loaded Biohybrid Scaffolds. Molecules. 2019; 24 (9): 1660. doi: 10.3390/molecules 24091660

21. Habraken W, Habibovic P, Epple M, Bohner M. Calcium phosphates in biomedical applica- tions: materials for the future? Materials Today. 2016; 19 (2).

22. Zhang B, Han Z, Duan K, Mu Y, Weng J. Multilayered pore-closed PLGA microsphere delivering OGP and BMP-2 in sequential release patterns for the facilitation of BMSCs osteogenic differentiation. J Biomed Mater Res Part A. 2018; Vol106A. p95-105. DOI: 10.1002/ jbm.a.36210

23. Shen XF, Zhang YX, Gu Y, Xu Y, Liu Y, Li B. Sequential and sustained release of SDF-1 and BMP-2 from silk fibroin-nanohydroxyapatite scaffold for the enhancement of bone regeneration. Biomaterials. 2016; 106: 205-216.

24. Mijiritsky E, Ferroni L, Gardin Ch, Bressan E, Zanette G, Piattelli A, Zavan B. Porcine Bone Scaffolds Adsorb Growth Factors Secreted by MSCs and Improve Bone Tissue Repair. Materials (Basel, Switzerland). 2017; 10 (9): 1054. doi: $10.3390 / \mathrm{ma1} 0091054$

Sofia Curbelo: sgcurbelo@gmail.com 